\title{
Effect of Cisapride on the Cholinergic Control Mechanisms of Gastrointestinal Motility in Dogs
}

\author{
Kazumoto FujII, Masazumi OKajIMA* and Katsufumi KAWAHORI* \\ Department of Physiology, School of Medicine, Hiroshima University and \\ *Department of Surgery, School of Medicine, Hiroshima University
}

\begin{abstract}
Fujii, K., Okajima, M. and Kawahori, K. Effect of cisapride on the cholinergic control mechanisms of gastrointestinal motility in dogs. Japanese Journal of Smooth Muscle Research, 24(1), 1-11, 1988 - The action of cisapride on physiological and disturbed gastrointestinal motor function was investigated in conscious and anesthetized dogs and the mechanism of action involved.

Regardless of the presence or absence of vagal innervation, administration of cisapride $(0.2 \mathrm{mg} \sim 1.0 \mathrm{mg} / \mathrm{kg}$ body weight, i.v.) during the quiescent period of interdigestive migrating contractions (IMC), induced non-migrating IMC-like motility in the entire gastrointestinal tract from gastric body to distal colon.

Administration of cisapride in the digestive state resulted in the excitatory response of increased amplitude of digestive peristalsis and strong IMC-like motility was not observed.

All of these excitatory responses in gastrointestinal motility disappeared by the administration of atropine $(0.05 \mathrm{mg} \sim 0.1 \mathrm{mg} / \mathrm{kg}$ body weight, i.v.). Furthermore, the excitatory response in gastrointestinal motility induced by cisapride in anesthetized dogs disappeared by the administration of TTX $(10 \mu \mathrm{g} / \mathrm{kg}$ of body weight, i.v.).

These results suggest that the excitatory action of cisapride on the gastrointestinal motility is based on its mechanism in which cisapride acts on the cholinergic neurones in the gastrointestinal wall to stimulate $\mathrm{ACh}$ release, resulting in the increase in gastrointestinal motility.

Cisapride caused powerful IMC-like motility in the ileum of animal with pseudoobstruction-like motor disturbance which had been seen after preparation of Thiry loop (ileum). This motility migrated from the proximal ileum to the Thiry loop and then to the distal ileum. Trimebutine maleate also demonstrated this effect, but metoclopramide and domperidone were ineffective.

Administration of cisapride at the doses $(0.2 \mathrm{mg} \sim 1.0 \mathrm{mg} / \mathrm{kg}$ body weight, i.v.) causing stimulated motor response in the gastrointestinal tract did not induce significant secretion of gastric acid, pancreatic juice and bile.
\end{abstract}

Key words: cisapride, interdigestive gastrointestinal motility, IMC-like motility, postprandial gastrointestinal motility, Thiry loop

Accepted for publication, September 25, 1987

藤井一元：広島大学医学部第二生理学教室

岡島正純, 川堀勝史：広島大学医学部第二外科学教室

于 734 広島市南区霞·1-2-3 


\section{Introduction}

Intramural cholinergic nerves project their axons to gastrointestinal smooth muscle and innervate it to elicite excitatory response though there are exceptions in a part of gastrointestinal tract.

In recent years, the existence has been reported of various endogenous substances which act either stimulatively (gastrin, CCK, susbtance P, neurotensin, GABA) or inhibitively (noradrenaline, dopamine, enkephalin, VIP), on ACh release (Vizi et al., 1973 ; Szurszewski, 1976 ; Pernow, 1983 ; Yau et al., 1983; Taniyama et al., 1985 ; Tanaka et al., 1985 ; Fujii et al., 1985).

Cisapride (cis-4-amino-5-chloro-N-(1-(3-(p-fluorophenoxy)propyl)-3-methoxy-4-piperidyl)-o-anisamide hydrate) has been reported to be a prokinetic (Schuurkes et al., 1984a, b), which acts by stimulating ACh release from cholinergic neurones in the gastrointestinal wall, similar to endogenous ACh release stimulants (Pfeuffer-Friederich et al., 1984).

However, administration of cisapride during interdigestive state caused non-migrating IMC-like motility of the gastrointestinal tract, but did not affect IMC itself (Suzuki et al., 1985). Furthermore, cisapride displays not only stimulative action on gastrointestinal motility in anesthetized animals, but also shows inhibition in some cases (Nakayama et al., 1985), indicating that cisapride demonstrates different efficacy depending on physiological conditions.

In the present study, we investigated the effect of cisapride on gastrointestinal motor function during interdigestive and post-prandial state in conscious dogs and its effect against pseudo-obstruction-like akinesia, and then discussed the role of the cholinergic regulatory mechanism of physiological gastrointestinal motility.

\section{Methods}

Using 11 adult healthy mongrel dogs weighting $10 \sim 15 \mathrm{~kg}$, the action of cisapride on physiological motility of various parts of the gastrointestinal tract (gastric body, antrum, duodenum, distal ileum as well as proximal and distal colon) were studied. In addition, the action of cisapride against pseudo-obstruction-like akinesia encountered after the preparation of Thiry loop was investigated.

Under anesthesia by pentobarbital sodium (Nembutal, Abbott, $25 \mathrm{mg} / \mathrm{kg}$ body weight, i.v.), force transducers (Star Medical, F-12IS) were sutured onto the serosal surface of the gastrointestinal tract to measure circular muscle contractions. The lead wires of the force transducers were connected to amprifier (Star Medical, FS-02) and multichannel pen-writing recorder (Graphtec, WK-3701), and gastrointestinal motility was recorded. Thiry loop (about $20 \mathrm{~cm}$ in length) was prepared at $15 \mathrm{~cm}$ proximal from the ileocecal junction and its motility were simultaneously recorded with those of the proximal and distal ileum of anastomosis site.

Feed was consisted of dogs food (Japan Clea, CD-5, $150 \mathrm{~g}$ ) mixed with bread gruel ( $200 \mathrm{cc}$ of hot water, $50 \mathrm{~g}$ of bread, and $25 \mathrm{~g}$ of skim milk) and allowed to swell (about $600 \mathrm{cal}$ ). This feed was supplied regularly to the dogs once daily and the same feed was also used when the meal stimulation was needed in the experiment.

In addition, the influence of the effective dose of cisapride for the gastrointestinal motility on gastric juice (11 non anesthetized gastric fistula dogs), pancreatic jujce and bile secretion (4 
anesthetized dogs) were also studied. Pancreatic juice secretion was studied by measuring the amount obtained at $10 \mathrm{~min}$ intervals from a polyethylene tube inserted from the minor duodenal papilla. Simultaneously, the amount of bile secretion was progressively measured by catheterization of a polyethylene tube into the common bile duct from the major duodenal papilla.

Drugs used in the experiment were cisapride (Janssen), domperidone (Janssen), metoclopramide (Sigma), trimebutine maleate (Tanabe Seiyaku), atropine sulfate (Tanabe Seiyaku) and tetrodotoxin (Sankyo). With the exception of atropine (bolus), these drugs were administered by continuous infusion from the cephalic vein using an infusion pump (Tokyo Rika, MP-3).

Since the gastric motor excitatory response to cisapride did not occur in a dose dependent way (Suzuki et al., 1985), most of the animals used in this experiment were injected at the dose of $0.5 \mathrm{mg} / \mathrm{kg}$ body weight. Some of the animals were injected at the doses of $0.2 \mathrm{mg} / \mathrm{kg}, 0.75$ $\mathrm{mg} / \mathrm{kg}$ and $1.0 \mathrm{mg} / \mathrm{kg}$ body weight.

Intravenous route was employed in order to avoid contractions induced by mechanical and chemical stimulation (not substantial pharmacological property) of this drug when administered orally.

\section{Results}

\section{Effect of cisapride on interdigestive gastrointestinal motility}

Fig. 1 shows motility in the gastric body and antrum caused by continuous intravenous injection of cisapride $(0.5 \mathrm{mg} / \mathrm{kg}$ body weight for $5 \mathrm{~min})$ during the quiescent period of IMC elapsing over 20 hours after giving food to the animal on the day prior to experiments. Immediately after completion of intravenous injection of cisapride irregular movements with low amplitude were observed in the gastric body, and $8 \mathrm{~min}$ after completion of the injection, the motility had become phasic (Fig. 1A). On the other hand in the antrum, clear motility of which the pattern was IMC-like was observed immediately after initiation of intravenous injection of cisapride (Fig. 1B). As these cases indicate, the motility caused by cisapride was not found to migrate from the gastric body to the antrum.

The motility caused by the injection of cisapride rapidly disappeared by the intravenous injection of atropine ( $0.05 \mathrm{mg} / \mathrm{kg}$ body weight) (Fig. 1).

In any portion of the small intestine, increase of the motility was observed clearly after the administration of cisapride during the quiescent period of IMC.

Fig. 2 shows motility of the distal ileum ( $5 \mathrm{~cm}$ orally from the ileocecal junction) of dogs in

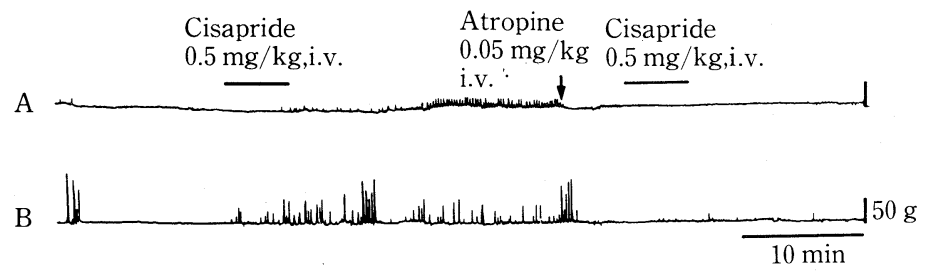

Fig. 1 Gastric motor excitatory responses caused by intravenous administration of cisapride (quiescent period of IMC) and the effect of atropine on this response

A : Gastric body motility

B : Antral motility (Natural IMC is shown on the left side) 
A

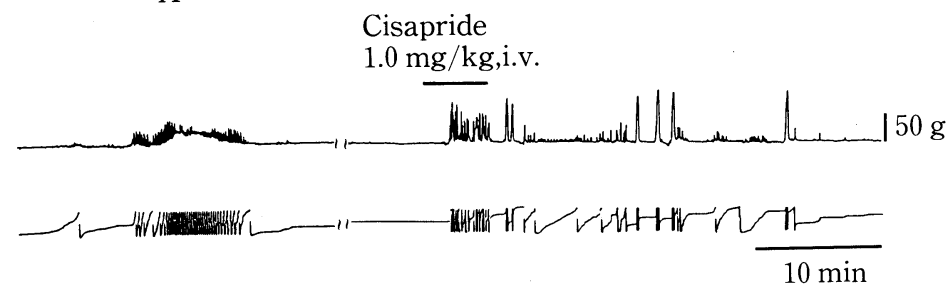

Fig. 2 Excitatory response in distal ileal motility caused by intravenous administration of cisapride (quiescent period of IMC)

Truncal vagotomized dog

Upper: IMC (A) and motor excitatory response by cisapride (B)

Lower: Integral curve of ileal motility

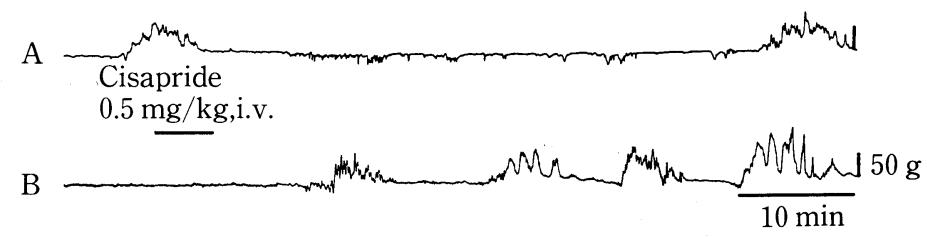

Fig. 3 Excitatory response of the distal colon to intravenous administration of cisapride (quiescent period of IMC)

A : Post-prandial motility

B : Motor excitatory response by cisapride

which the abdominal branches of the vagus nerve were cut at subdiaphragm. Administration of cisapride ( $1.0 \mathrm{mg} / \mathrm{kg}$ body weight, i.v.) during the quiescent period of IMC (Fig. 2A) resulted in a lower frequency of contractions with higher amplitude (Fig. 2B) at $2 \mathrm{~min}$ after initiation of administration, compared with the IMC shown in Fig. 2A.

Fig. 3A shows naturally-produced IMC of the distal colon. In these cases, the continuous IMC which lasted for 7 10 min appeared at $48 \sim 62 \mathrm{~min}$ intervals. Intravenous injection of cisapride $(0.5 \mathrm{mg} / \mathrm{kg}$ body weight) during the quiescent period of IMC resulted in IMC-like motility appearing at $4 \mathrm{~min} 40 \mathrm{sec} 8 \mathrm{~min}$ intervals from $8 \mathrm{~min}$ after completion of the intravenous injection (Fig. 3B). A similar response was also observed in the proximal colon.

Just as the case of stomach (Fig. 1), the motility of the small intestine (Fig. 2B) and colon (Fig. 3B) caused by administration of cisapride during the quiescent period of IMC did not appear under the influence of atropine.

Clear differences were not observed in the excitatory response in gastrointestinal motility by administration of cisapride at the doses from $0.2 \mathrm{mg} / \mathrm{kg}$ body weight to $1.0 \mathrm{mg} / \mathrm{kg}$ body weight.

\section{Effect of cisapride on post-prandial gastrointestinal motility}

Fig. 4 shows the stimulating effect of cisapride on digestive motility in the gastric antrum caused by giving the animals test meal in the interdigestive period after $20 \mathrm{hr}$ following feeding on the day prior to the experiment. Administration of cisapride $(0.75 \mathrm{mg} / \mathrm{kg}$ body weight injected over $5 \mathrm{~min}$ ) during the period while digestive motility were continuing, resulted in a clear increase in the amplitude of digestive motility from $3 \mathrm{~min}$ after initiation of intravenous injection. It can be seen that the feature of excitatory response in digestive motility caused by 

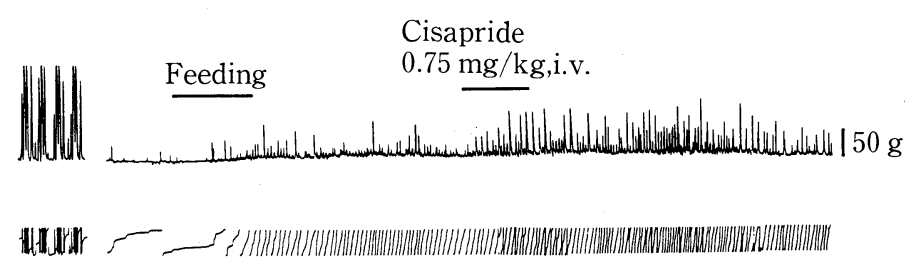

$10 \mathrm{~min}$

Fig. 4 Excitatory response in post-prandial gastric antral motility caused by cisapride

Upper: IMC (left side) and excitatory response in post-prandial motility caused by cisapride

Lower: Integral curve of gastric motility

4h after feeding

Cisapride

$0.5 \mathrm{mg} / \mathrm{kg}$,i.v.

A
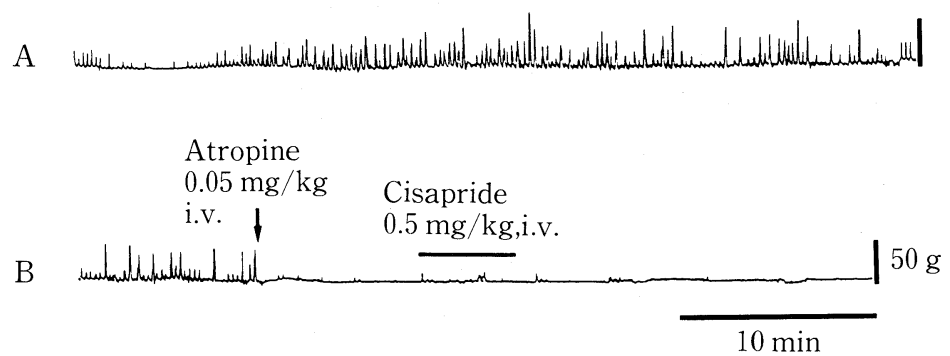

Fig. 5 Excitatory response of post-prandial duodenal bulb motility caused by cisapride and the effect of atropine on this response

A : Excitatory response in post-prandial motility

B : Effect of atropine on cisapride-induced excitatory response

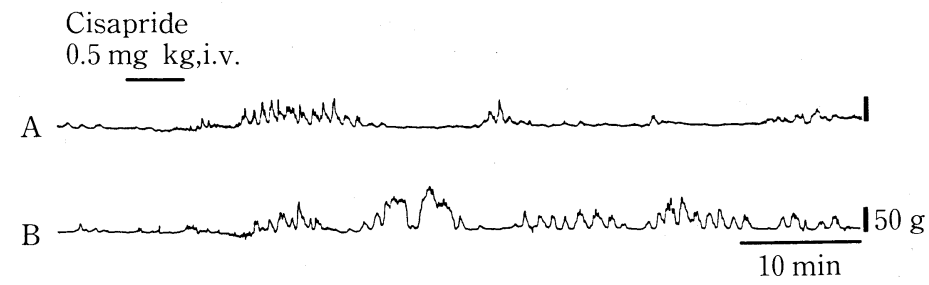

Fig. 6 Excitatory response in post-prandial colon motility caused by cisapride A : Proximal colon motility

B : Distal colon motility

cisapride is increase in the amplitude of peristaltic movements. In order to make a comparison with this response, an example of the IMC presented in this animal are shown in the left side of Fig. 4.

Excitatory response in digestive motility caused by administration of cisapride, disappeared with the intravenous injection of atropine $(0.05 \sim 0.10 \mathrm{mg} / \mathrm{kg}$ body weight).

Excitatory response in digestive motility of the duodenal bulb caused by cisapride and the effect on this response by atropine are shown in Fig. 5.

Administration of cisapride $(0.5 \mathrm{mg} / \mathrm{kg}$ body weight injected intravenously over $5 \mathrm{~min})$ in the period during which the amplitude of digestive motility became smaller about $4 \mathrm{hr}$ after 


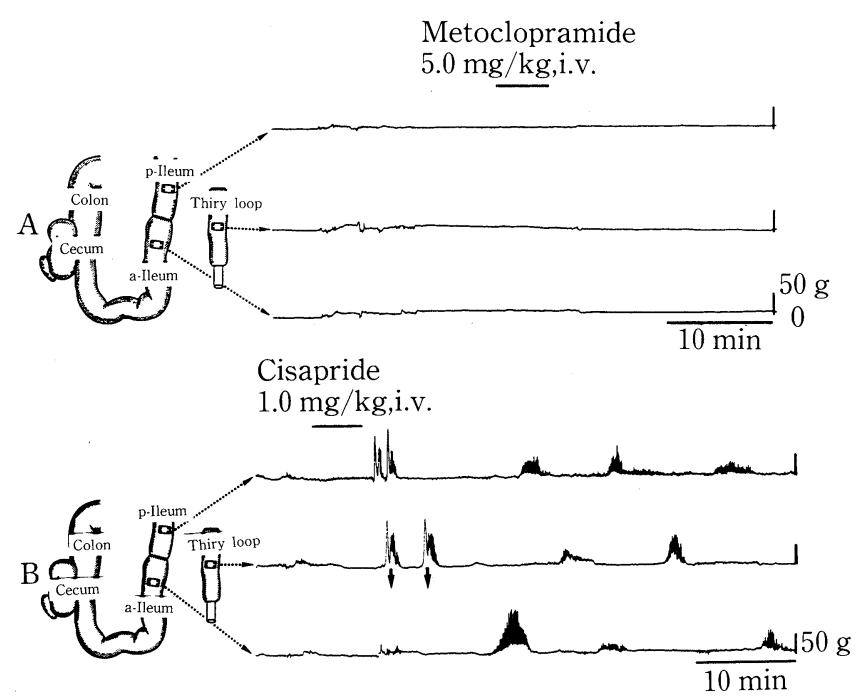

Fig. 7 Effect of intravenous injection of cisapride on motor disfunction resembling pseudoobstruction of the ileum

A : Metoclopramide intravenous injection

B : Cisapride intravenous injection

p-ileum : proximal ileum

d-ileum : distal ileum

From above, motility of the p-ileum, Thiry loop and d-ileum

$\downarrow$ : Evacuation of contents

feeding (Fig. 5A, left edge) resulted in clearly increased amplitude from 4 min after the initiation of injection (Fig. 5A). However in the frequency of contractions, no significant variation was observed.

Intravenous injection of atropine $(0.05 \mathrm{mg} / \mathrm{kg}$ body weight) during the period of excitatory response caused by cisapride administration, resulted in potent inhibition of the responce though a slight level of motility remained (Fig. 5B). Under the influence of atropine, readministration of cisapride at an equivalent dose to that of the control (Fig. 5A) did not result in reappearance of increase in duodenal motility (Fig. 5B).

Cisapride

$1.0 \mathrm{mg} / \mathrm{kg}$,i.v.

A

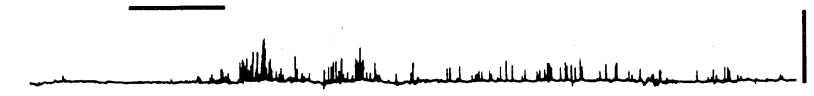

1h after TTX i.v. $(10 \mu \mathrm{g} / \mathrm{kg})$

Cisapride

$1.0 \mathrm{mg} / \mathrm{kg}$,i.v.

B $50 \mathrm{~g}$

$$
10 \mathrm{~min}
$$

Fig. 8 Action of tetrodotoxin (TTX) on excitatory response to cisapride in ileal motility Anesthetized dog

A : Excitatory response to cisapride in ileal motility

B : Effect of cisapride in the presence of TTX 
Table 1 Spread and pattern of motor responses in gastrointestinal tract caused by administration of cisapride, domperidon, metoclopramide and trimebutine maleate in the interdigestive state and effects of atropine and TTX on these motor responses

\begin{tabular}{|c|c|c|c|c|c|c|c|c|}
\hline \multirow[b]{2}{*}{ drugs } & \multicolumn{6}{|c|}{ functional range of drugs } & \multirow{2}{*}{$\begin{array}{l}\text { pattern of } \\
\text { excitatory } \\
\text { response }\end{array}$} & \multirow{2}{*}{$\begin{array}{c}\text { influence of } \\
\text { atropine } \\
\text { and TTX }\end{array}$} \\
\hline & $\begin{array}{l}\text { gastric } \\
\text { body }\end{array}$ & antrum & duodenum & ileum & $\begin{array}{l}\text { proximal } \\
\text { colon }\end{array}$ & $\begin{array}{l}\text { distal } \\
\text { colon }\end{array}$ & & \\
\hline cisapride & + & + & + & + & + & + & IMC-like & inhibited \\
\hline domperidone & + & + & + & \pm & \pm & \pm & PPM-like & inhibited \\
\hline metochlopramide & + & + & + & \pm & \pm & \pm & PPM-like & inhibited \\
\hline $\begin{array}{l}\text { trimebutine } \\
\text { maleate }\end{array}$ & + or - & + or - & + & + & + & + & IMC-like & unaffected \\
\hline
\end{tabular}

$+:$ excitation $\pm:$ no effect $-:$ inhibition

IMC : interdigestive migrating contractions

PPM : post-prandial motility

Fig. 6 shows motor stimulating pattern in the proximal colon (Fig. 6A) and distal colon (Fig. 6B) caused by intravenous administration of cisapride $(0.2 \mathrm{mg} / \mathrm{kg}$ body weight, for $5 \mathrm{~min})$ $4 \mathrm{hr}$ after feeding. Before intravenous injection of cisapride digestive motility were irregular with a low amplitude, but after the injection, the motility was clearly augumented. Response in the two colon sites appeared almost simultaneously and migration from the proximal to the distal colon was not observed. The amplitude of these responses were merely $1 / 3$ rd that of IMC.

3. Effect of cisapride against motor disturbances observed after preparation of Thiry loop (ileum)

In 1 case in which an about $20 \mathrm{~cm}$-long Thiry loop (Fig. 7A, left side) was constructed chronically at a distance of $15 \mathrm{~cm}$ from the ileocecal junction proxymally (in this dog a gastric fistula was prepared at the gastric body), ileal and loop motor disturbances and various symptoms such as reflux of small intestinal contents to the stomach and vomiting immediately after cosuming a small amount of milk (vomiting of pasty stomach contents) appeared over several days postoperatively. Domperidone ( $5 \mathrm{mg} / \mathrm{kg}$ body weight, i.v.) and metoclopramide (5 $\mathrm{mg} / \mathrm{kg}$ body weight, i.v., Fig. 7A) were administered in order to suppress vomiting and restore motor function, but ileal and Thiry loop motility was not produced.

Administration of cisapride ( $1.0 \mathrm{mg} / \mathrm{kg}$ body weight by intravenous injection over $5 \mathrm{~min}$ ) resulted in immediate appearance of potent proximal ileal motility from the anastomosis. This was followed by repeated IMC-like motility for about $3 \mathrm{hr}$. This motility in the proximal ileum migrated first to the Thiry loop and continuously migrated to the anastomosis and to the distal ileum (Fig. 7B).

The contents which had accumulated within the loop were evacuated when the initial potent contractions migrated to the Thiry loop from the proximal ileum (Fig. 7B, $\downarrow$ ).

Trimebutine maleate $(3 \mathrm{mg} / \mathrm{kg}$ body weight, i.v.) demonstrated similar effect to cisapride in this case of motor disfunction. 
4. Effect of tetrodotoxin (TTX) on excitatory response in gastrointestinal motility caused by administration of cisapride

Fig. 8A shows the motor stimulating response of ileum caused by intravenous injection of cisapride $(1.0 \mathrm{mg} / \mathrm{kg}$ body weight) in dogs anesthetized with pentobarbital sodium. The results of intravenous injection of cisapride after administration of TTX $(10 \mu \mathrm{g} / \mathrm{kg}$ body weight by intravenous injection over $30 \mathrm{~min}$ under artificial respiration) are shown in Fig. 8B. It can be seen that ileal motility did not occur at all.

The spread and pattern of excitatory response of gastrointestinal motility to cisapride administred during the interdigestive state, as well as the effects of atropine and TTX are compared in Table 1 with those of domperidone, metoclopramide and trimebutine maleate.

5. Influence of cisapride on the secretion of gastric acid, pancreatic juice and bile

In order to determine whether cisapride at the doses causing augmentation in gastrointestinal motility has any effects on secretory function, the influence of cisapride on the secretion of gastric acid, pancreatic juice and bile was investigated. Gastric secretion in conscious gastric fistula dogs was completely unaffected by intravenous administration of cisapride in the dose from $0.2 \mathrm{mg} / \mathrm{kg}$ of body weight to $0.75 \mathrm{mg} / \mathrm{kg}$ of body weight with respect to the amount of basal gastric acid secretion. However, at the dose of $1.0 \mathrm{mg} / \mathrm{kg}$ body weight, some animals (3 out of $8 \mathrm{dogs}$ ) demonstrated extremely weak gastric acid secretion. This response disappeared completely with the administration of atropine $(0.05 \mathrm{mg} / \mathrm{kg}$ body weight, i.v.) (dotted line in Fig. 9). However, these gastric fistula dogs displaying secretion of gastric acid did not show gastric acid secretion at the same dose of cisapride in a separate experiment.

The amount of basal pancreatic juice secretion $(28.5 \mu l \sim 35.4 \mu l / 10 \mathrm{~min})$ and the amount of basal bile secretion $(0.4 \mathrm{ml} \sim 0.9 \mathrm{ml} / 10 \mathrm{~min})$ in 24-hour fasted dogs was not affected by intravenous injection of cisapride in the doses from $0.2 \mathrm{mg} / \mathrm{kg}$ body weight to $1.0 \mathrm{mg} / \mathrm{kg}$ body

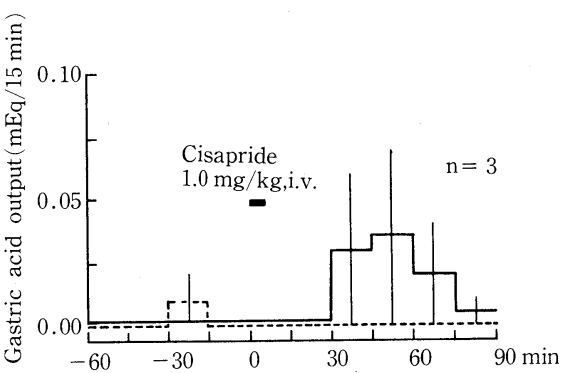

Fig. 9 Cases with cisapride-induced gastric acid secretion. Solid line: before atropine administration. Dotted line : after atropine administration weight.

\section{Discussion}

As shown by results $\mathrm{A}$ and $\mathrm{B}$ of the present study, administration of cisapride to conscious dogs during the interdigestive or digestive period resulted in excitatory action on gastrointestinal motility in all portions of the gastrointestinal tract from the stomach through the duodenum and ileum to the proximal and distal colon, regardless of the presence or absence of the vagus nerve (Fig. 2).

Furthermore, the excitatory response caused by cisapride disappeared with administration of atropine (Schuurkes et al., 1984 ; Van Nueten et al., 1984 ; Nakayama et al., 1985 ; Suzuki et al., 1985; Nishioka et al., 1986). In addition, in anesthetized dogs, motor excitation of intestine caused by cisapride disappeared by administration of TTX (Fig. 8B). 
These results are consistent with the mechanism of excitation of gastrointestinal motility in which cisapride acts on the cholinergic neurones in the gastrointestinal wall, thereby stimulating ACh release (Pfeuffer-Friederich et al., 1984) with the result that gastrointestinal motility is stimulated via the muscarinic receptors of smooth muscle (Schuurkes et al., 1984).

However, substantial differences between the pattern of excitatory response in gastrointestinal motility caused by cisapride were observed in the interdigestive and digestive periods. In other words, administration of cisapride during the quiescent period of IMC resulted in IMClike motility (Fig. 1, 2 and 3; Suzuki et al., 1985; Nishioka et al., 1986). However, administration during the digestive state led to the excitatory response pattern in which the amplitude of peristaltic movements increased.

Suzuki et al. (1985) reported that differences between IMC-like motility induced by cisapride and natural IMC are the absence of concurrent elevation of blood motilin level and the absence of migration to the distal area. However, a feature common to both of motor pattern is disappearance by the administration of atropine and inhibition by gastrointestinal hormones such as CCK and gastrin.

In this study, it is difficult to investigate the non-migrating property of IMC-like motility caused by cisapride due to the small number of animals in which motilities of several gastrointestinal tracts were recorded simultaneously. Despite this, the results shown in Fig. 1 and Fig. 6 are considered to show the non-migrating property of IMC-like motility caused by administration of cisapride.

However in this study, in animals with ileal motor disfunction resembling pseudo-obstruction (Camilleri et al., 1986) observed after the preparation of Thiry loop (Fig. 7A), IMC-like motility induced in the proximal ileum by intravenous injection of cisapride clearly migrated to the Thiry loop and then to the distal ileum (Fig. 7B).

These results indicate that the action of cisapride varies depending on variation in physiological conditions. At the present time, details of the mechanism of action of these phenomena are not available, but its elucidation is expected to provide an important clue to the explanation of the mechanism of action of the physiological factors participating in cholinergic motor regulation of gastrointestinal motility (Vizi, 1973; Szurszewski, 1976 ; Pernow, 1983; Yau et al., 1983 ; Taniyama, 1985; Tanaka et al., 1985; Fujii et al., 1985). The contents which accumulated in the Thiry loop, were evacuated by the strong initial contractions appearing in the loop by cisapride administration (Fig. 7B). The pattern of these contractions in the loop were identical to that of the strong contractions observed in the proximal ileum of anastomotic region. Therefore, it is considered that at the time of strong contractions in the proximal ileum, the contents accumulating in the proximal ileum will be transported through the anastomotic region to the distal ileum.

These results indicate a part of the mechanism of cisapride efficacy in accerelating and improving gastric emptying and gut transit in cases with pseudo-obstruction in which these processes are delayed extremely compared to healthy persons (Camilleri et al., 1986).

Administration of cisapride in digestive state did not result in strong IMC-like motility as when administered in the interdigestive state, but caused a excitatory response which consisted mainly of increase in the amplitude of digestive motility (Fig. 4 6). 
The main mechanism causing excitation of gastric and intestinal motility in digestive state is stimulation of ACh release from cholinergic neurones in the gastrointestinal wall by gastrin, which is released due to the food stimulation (Chemical stimulus of the stomach contents). Histamine released from histamine-secretory cells in the gastrointestinal wall as a result of stimulation by gastrin, leads to excitation of gastrointestinal smooth muscle via the histamine $\mathrm{H}_{1}$ receptor (Fujii et al., 1981) and this mechanism is believed to be participating in causing the increased motility (Fujii et al., 1985). Consequently, it was expected that cisapride administered in digestive state, in combination with endogenous gastrin released due to the stimulus of food, synergistically stimulated the release of ACh from the cholinergic neurones in the gastrointestinal wall (Pfeuffer-Friederich, 1984), thereby causing the powerful contractions. However, the same powerful contractions as observed during the interdigestive state were not observed during the digestive state.

One hypothesis for this finding is considered to be that during digestive period, ACh release is tonically inhibited by noradrenaline via the $\alpha_{2}$ adrenergic receptor on cholinergic neurones in the gastrointestinal wall (Fujii et al., 1986), which may be a protective mechanism to prevent excessive promotion of post-prandial motility.

The pattern and spread of the excitatory response caused by administration of cisapride during the interdigestive state and the effects on this of atropine and TTX were compared in Table 1 with those of other prokinetics presently in wide clinical use. Result of the comparison indicates the diverse nature of the excitatory mechanism in gastrointestines as well as the existence of unknown excitatory mechanisms. For example, excitatory responses in gastric and duodenal motility caused by domperidone and metoclopramide, disappear by the administration of atropine or TTX (Table 1), similarly to the response caused by cisapride, indicating that these excitatory responses occur via a cholinergic mechanism. However, examination of the excitatory response pattern reveals that an IMC-like response occurs in response to cisapride, while a response resembling post-prandial motility occurs after administration of domperidone and metoclopramide (Table 1). This difference in pattern stems from the fact that excitatory response to domperidone and metoclopramide results from removal of tonic inhibition of dopamine on ACh release from the cholinergic neurones in the gastrointestinal wall (Kasuya et al., 1985), while the excitatory response to cisapride results from stimulation of ACh release from the cholinergic neurones in the gastrointestinal wall. However, differences in these mechanisms of action which are now clarified connot give appropriate explanation to the different pattern, suggesting the existence of unknown mechanisms.

With respect to spread of the effect, cisapride and trimebutine induced an IMC-like motility in all portions of the tract from the stomach to the colon, but metoclopramide and domperidone did not act on lower sites of the tract such as the ileum and colon. Furthermore, the trimebutine maleate-induced response was not affected by atropine or TTX (Table 1). These findings also indicate themes for future study to elucidate the excitatory mechanism of gastrointestinal motility.

At the doses of cisapride used in this experiment $(0.2 \sim 1.0 \mathrm{mg} / \mathrm{kg}$ body weight, i.v.), no significant effects on the secretion of gastric, pancreatic and bile juices were observed.

This finding indicates that the cholinergic innervation for the exocrine cells is less domi- 
nant than that for the gastrointestinal smooth muscle.

In some of the animals cisapride at a dose of $1.0 \mathrm{mg} / \mathrm{kg}$ body weight by intravenous injection produced extremely low levels of gastric acid secretion which atropine $(0.05 \mathrm{mg} / \mathrm{kg}$ body weight, i.v.) inhibited (Fig. 9). However, the gastric fistula dogs demonstrating this response did not show gastric acid secretion in a separate experiment. Consequently, it is considered that gastric acid secretion induced by administration of cisapride occurs as a result of the added effect of ACh release induced by cisapride at a time, when for some reason, the cholinergic gastric acid secretory mechanism threshold is reduced.

\section{Acknowledgements}

The authors wish to express our thanks to Janssen-Kyowa Co., Ltd. and Yoshitomi Pharmaceutical Industries., Ltd. who supplied the cisapride used in this experiment.

\section{References}

Camiller, M., Brown, M.L. and Malagelada, J-R. (1986). Impaired transit of chyme in chronic intestinal pseudo-obstruction. Gastroenterology 91 : 619-626.

Fujii, K., Takasugi, S. and Toki, N. (1981). Effect of cepharanthine on neuro-humoral excitatory responses of gastric movement in dog. Jpn. J. Physiol. 31: 613-623.

Fujii, K., Kawahori, K. and Okajima, M. (1987). Effects of famotidine, pirenzepine and tetrodotoxin on pentagastrin-induced gastric acid secretion in dogs. J. Physiol. Soc. Japan 49: 393.

Fujii, K. and Mukai, M. (1985). Neurohumoral mechanisms of excitation of gastric motility in the dog. In: Gastrointestinal Function. Edited. by Kasuya, Y. et al., Excerpta Medica, Tokyo, p. $15-27$.

Fujii, K., Mukai, M. and Okajima, M. (1985). Neural and neurohumoral factors participating in post-prandial gastric motility. Jpn. J. Smooth Muscle Res. 21: 253-255.

Fujii, K., Okajima, M. and Kawahori, K. (1986). Effect of $\alpha_{2}$-adrenergic receptor blockade on postprandial gastrointestinal motility. Jps. J. Smooth Muscle Res. 22: 202-205.

Kasuya, Y. and Urushitani, T. (1985). Pharmacology of gastrointestinal motility. B. Peripheral Acting Drugs. Gastrointestinal Motor function Regulators. In: Fundamental and Clinical Medicine. Edited by Miyoshi, A. and Itoh, Z. First Edition. Iyaku Journal Co., Tokyo, p. 116-169.

Nakayama, S., Neya, T. and Yamasato, T. et al. (1985). Effect of cisapride on the motility of digestive truct in dogs and guinea pigs. Jpn. J. Smooth Muscle Res. 21 : 1-9.

Pernow, B. (1983). Substance P. Pharmacological Reviews 35: 86-141.

Pfeuffer-Friederich, I. and Kilbinger, H. (1984). Facilitation and inhibition by 5-hydroxytriptamine and R51619 of acetylcholine release from guinea-pig myenteric neurones. Proc. 9th int. symp. on gastrointestinal motility. Edited by Roman, C., NTP Press, Lancaster, p. 527-534.

Schuurkes, J.A.J. and Van Nueten, J.M. (1984a). Control of gastroduodenal coordination: dopaminergic and ccholinergic pathways. Scand. J. Gastroenterol. 19 (Suppl. 92) : 8-12.

Schuurkes, J.A.J. and Van Nueten, J.M. (1984b). Motor stimulating properties of cisapride. In: Proc. 2nd. Eur. Symp. on gastrointestinal motility. Oxford, p. 96.

Suzuki, T., Nakao, M. and Nakamura, T. et al. (1985). Effect of cisapride on contractile activity of the gastrointestinal truct. Jpn. J. Smooth muscle Res. 21 : 139-149.

Szurszewski, J.H. (1976). Neural and humoral determination of gastric antral motility. In: Physiology of smooth muscle. Edited by Bülbing, E. and Shuba, M.F., Raven Press, New York, p. 379-383. 
Tanaka, C. and Kusunoki, M. (1985). Mechanism of gastrointestinal motor regulation. A. Autonomic nervous regulation (Central). Gastrointestinal motor function regulators. In: Fundamental and Clinical Medicine. Edited by Miyoshi, A. and Itoh, Z. Iyaku Journal Co., Tokyo, p. 98-107.

Taniyama, K., Honda, S. and Tanaka, C. (1985). Autoreceptors regulate $\gamma-\left({ }^{3} \mathrm{H}\right)$ aminobutyric acid release from the guinea pig small intestine. Neurosci. Lett. 55 : 245-248.

Vizi, S.E., Bertaccine, G., Impicciatore, M., et al. (1973). Evidence that acetylcholine released by gastrin and related polypeptides contributes to the effect on gastrointestinal motility. Gastroenterology 64 : 268-277.

You, W.M., Verdum, P.R. and Youther, M.L. (1983). Neurotensin-A modulator of enteric cholinergic neurones in the guinea pig small intestine. Eur. J. Pharmacol. 95 : 253-258. 